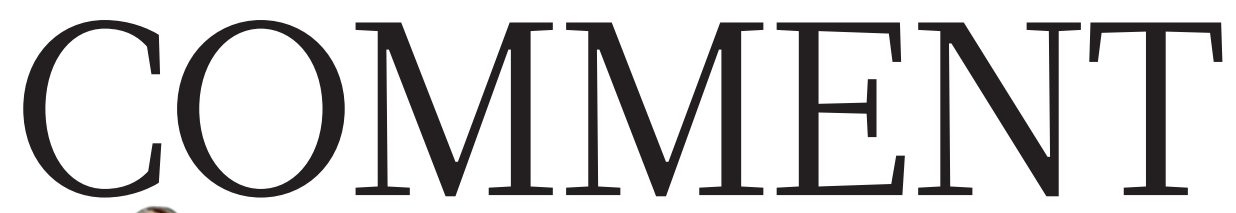

GEOSCIENCE A lesson for the future in a history of how life shaped Earth $\mathbf{p . 4 6 0}$
HISTORY How novels elevated sensibility above mechanical views p.462
CHEMISTRY Preserving the scent of endangered flowering plants $\mathbf{p . 4 6 4}$
PSYCHOLOGY On the definition, treatment and prediction of stuttering $\mathbf{p . 4 6 5}$
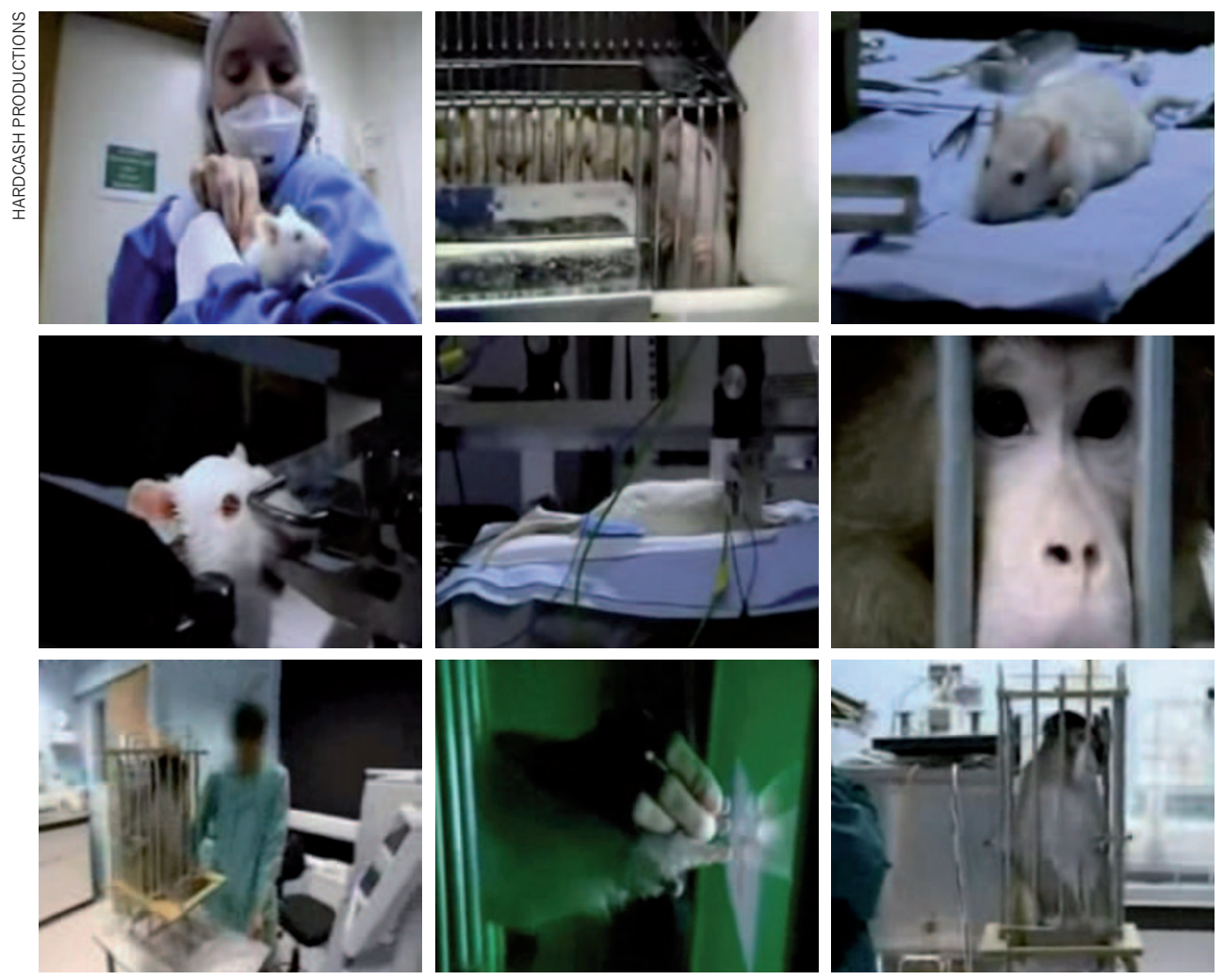

Scenes from the film Monkeys, Rats and Me show how animal research is done in Oxford, UK.

\title{
Animal testing: TV or not TV?
}

Two views on whether scientists who believe that animal experimentation is necessary should become public advocates, or work quietly behind the scenes.

\section{POINT}

\section{Somebody has to speak out}

Tipu Aziz and John Stein, John Radcliffe Hospital, Oxford, UK.

$\mathrm{I}$ was not without trepidation that, in 2006, we appeared on prime-time national television to talk about our work on macaque monkey models of Parkinson's disease. After all, there have been severe repercussions for researchers in the United Kingdom. In 1985, Molotov cocktails were thrown at the home of Nobel prizewinner John Vane, then director of research at the Wellcome Foundation. In 2004, activists exhumed the body of Gladys Hammond, just because she was the late mother-in-law of a breeder of guinea pigs for animal experiments (this at least provoked public outrage). Colin Blakemore, a

\section{COUNTERPOINT Avoid the camera}

Ranga Yogeshwar, science TV presenter near Cologne, Germany.

$\mathrm{T}$ Television is how most people get their news these days: it brings remote lands closer, and provides emotionally compelling closeups of individuals affected by world events. But it is a totally unsuitable platform for delivering complicated information or detailed discussion. My advice for scientists involved in the ethically complex field of animal research? Stay as far away from the camera as possible.

I say this as a science TV presenter and former scientist. I was once a particle physicist and am now on the board of a couple of Max Planck institutes, and I have hosted science television in Germany since $>$ 
POINT: SOMEBODY HAS TOSPEAK OUT > neurobiologist at the University of Oxford and former head of the UK Medical Research Council, is one of the few scientists who has been consistently brave enough to defend his animal research in public. The result for him has been assaults by masked terrorists, bombs sent to his children and letters laced with razor blades: in short, two decades of attacks and abuse.

Activist intimidation and violence has understandably led many scientists to conclude that it is not safe to speak in public about their work. This silence has opened the way for anti-vivisectionists to misrepresent animal experiments as useless, cruel and outdated. In one debate in which we were involved, the audience were told that no animals were used in the discovery of insulin or of penicillin. This is not true: insulin was discovered with the help of experimental dogs, and the first preparations of penicillin were tested on mice. Such bending of the facts is easy if there is nobody to present the other side.

The one-sidedness of the debate has had some disastrous effects. In 1997, the University of Cambridge, UK, announced amid great fanfare a plan for a new primate-research centre, supported by $£ 24$ million (US\$39 million) from the Wellcome Trust. But constant harassment of staff and members of the public by animal activists led to loss of local support, and in 2004 the university abandoned the project. Remarkably, not a single scientist who might have made use of the facility dared to defend the need for it in public.

We have been able to show that it doesn't have to be this way. In 2004, construction began on a large animal-research facility in Oxford that would also house primates. Soon after, extremists set fire to the contractor's offices, and construction was stopped for more than a year. Our research towards better Parkinson's disease treatments was in grave jeopardy. For some time we had been urging the University of Oxford's central management to be more proactive and explain to the public why animal experiments are so important without success. So, after anxious debate with our families, despite the risks, we decided to speak up. Someone needed to do something. Otherwise we, too, would lose the battle.

\section{INSULTS AND DEATH THREATS}

We had the advantage that we could tell a fairly simple story about how our primate research was feeding directly through to improvements in neurosurgery, and we had patients who were so grateful that they too agreed to speak up. We thought this might help to counteract the misinformation being put out by SPEAK (an animal-rights group originally founded as Stop Primate Experiments at Cambridge (SPEAC), which had moved its attentions to Oxford).

We gave an interview to the Oxford Times in 2004 explaining that the new building was needed to provide better conditions for experimental animals, which are the basis for virtually all medical advances and ensure the safety of any new drugs. This earned us a storm of insults, death threats by e-mail and letter, and, sadly, strong criticism from many of

\section{"Remaining silent is not an option for scientists engaged in animal research; anyone can use Google to look up what a researcher does."} our colleagues for 'putting their lives at risk'. Nature picked up what we were trying to do, however, and wrote a piece on the need for the facilities and the need for educating the public to appreciate their value (see Nature 430, 597; 2004).

We two scientists alone did not make much of an impact until a 16-year-old student, Laurie Pycroft, came upon a SPEAK march in Oxford. He bravely joined in with a banner supporting animal testing, until he was summarily ejected. He then set up a website, using his slogan 'Pro-Test', and rapidly found himself supported by hundreds of students from Oxford and elsewhere. We were honoured to be invited to join them. Together, we decided to organize a Pro-Test demonstration to bring the debate about animal research to the attention of the public.

Pro-Test led the first ever UK march in support of the benefits of

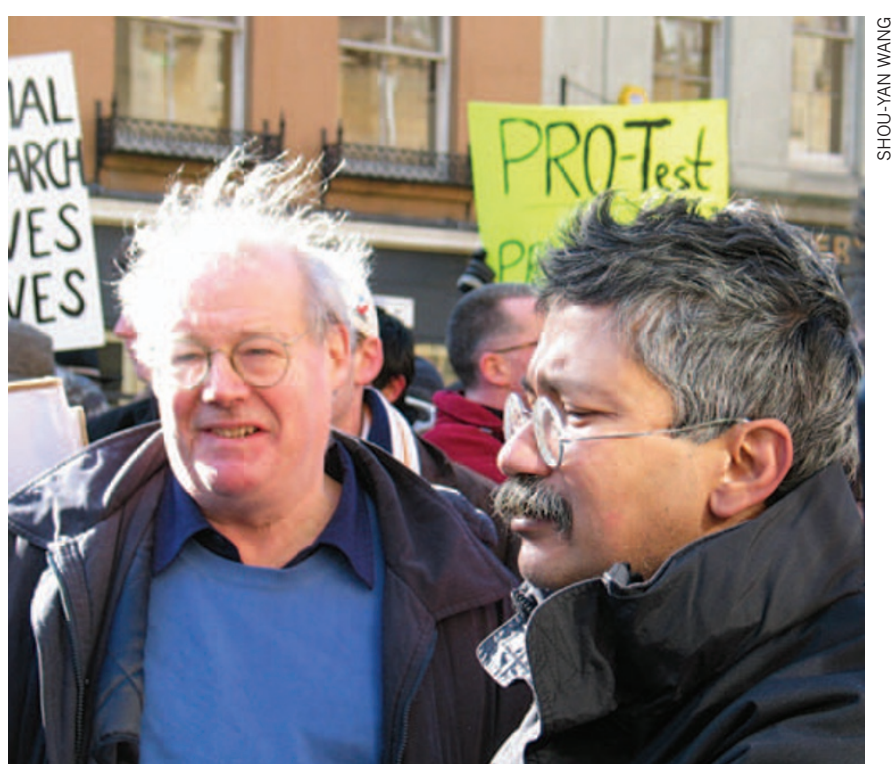

John Stein and Tipu Aziz at the first Pro-Test rally, in Oxford, UK, in 2006.

animal research, which we were proud to lead with our local Member of Parliament, Evan Harris. We were joined by more than 800 supporters, which was, as The Times reported, five times more than SPEAK could muster. We were pleased by the considerable media attention that this gained, and contacted the BBC with an idea to make a documentary about our and others' animal research in Oxford. With some difficulty we managed to overcome the objections of both the hospital and the university authorities against allowing filming in our animal laboratories. The end product, Monkeys, Rats and Me with journalist Adam Wishart, aired in November 2006. This led to a proper national discussion. A debate was featured on the renowned BBC current-affairs programme Newsnight. And the subject of animal experimentation is now often in the 'general studies' curriculum of students hoping to move on to university.

By the end of 2006, former primer minister Tony Blair had committed the Labour Party to the need for animal research, and work on the Oxford facility began again under utmost security. During this period, injunctions were issued against known activists, banning them from approaching the construction site and the residences of scientists involved in animal research, including us. The police were impressively efficient and we felt well protected. By November 2008, the laboratory was completed. The state-of-the-art facilities are admired by almost everyone except for the small bunch of anti-vivisectionist protestors who still demonstrate outside every Thursday.

Unfortunately, the immense security and very high cost of macaques, which, in the United Kingdom, have to be purpose-bred if needed for research, have led to as much as a fifty-fold increase in the cost of carrying out primate research in the country over the past 20 years. This, more than activists' direct threats, is driving research abroad, often to countries where animal welfare is less scrupulously protected. If activists really care about animal well-being they should actually encourage the work to take place in the United Kingdom.

In this electronic age, remaining silent is not an option for scientists engaged in animal research; anyone can use Google to look up what a researcher does. The sensible thing is to be proactive and prepared to defend our work. The public needs to hear all sides of the story. Every scientist must make his or her own moral judgements on this issue, but we would make the same decision again.

Tipu Aziz is in the Department of Neurosurgery, John Radcliffe Hospital, Oxford OX3 9DU, UK. John Stein is in the Department of Physiology, Anatomy and Genetics, Oxford OX1 3PT, UK. e-mail:john.stein@dpag.ox.ac.uk 
COUNTERPOINT: AVOIDTHECAMERA > the 1980s. One programme that I write and host, Quarks \& Co, gets some 1.5 million viewers a week, and another, Die große Show der Naturwunder (The Great Natural Wonder Show), is aired four times a year and gets one of the highest viewing figures of any show in Germany: about 5 million to 8 million people.

My goal is not to court ratings, but to present content honestly. I try to fight against the current trends of over-simplifying the news, over-playing the implications of research or chasing human-interest stories above all else. But I know that some stories simply don't work well on television. I can remember only one time that my show has tackled animal research, and even then the point was not to show its necessity, but to highlight work on alternatives. In that way we could portray scientists as 'the good guys'.

The problem is that on television, emotionally-charged pictures rule. Scenes of seal cubs clubbed to death precipitated a worldwide campaign against furs. It was gruesome pictures coming out of Vietnam that led to the end of that war. By the same token, film sequences of animal experimentation trigger intense reactions in viewers. Scientists are charged with cruelty and the accusation cannot be countered with arguments: the screech of a monkey or whine of a dog drowns out every possible justification. Researchers I know have told me that they themselves don't want to watch scenes of animal experimentation. The typical reaction is disgust - in my opinion, for good reason.

The ethics of animal experimentation are not simple. Although it is clearly a part of advancing medical science, there are times when its use is debatable. In the pharmaceutical industry, some new drugs are developed because they are expected to provide a financial payoff, even though effective drugs for the condition in question already exist. We might ask whether it is really justified to kill animals for that. I once worked at a nuclear reactor where cancer research was being done. I had an argument with one scientist because I thought that he was working in such a sloppy way that much of his data, produced at the expense of dozens of rats, meant nothing. Doing an animal experiment needs as much care as landing a jumbo jet: it requires not just a system of strict rules and regulations, but also personal dedication to best behaviour on behalf of everyone involved.

Even in the academic world, there is no consensus about what counts as good, necessary animal research. This kind of moral complexity does not come across well on television. Viewers can and do seek refuge by turning to another channel if a programme is boring or demanding. The length of stay on a given channel has dropped spectacularly

over the past few decades, in part because of the introduction of dozens more channels - for Quarks \& Co, a 45-minute show, viewers watch on average 23 minutes. In response, the mass media tries to be clear-cut and simple. It draws a line between good and evil, culprit and victim, winner and loser.

An audience presented with multiple opinions and viewpoints tends not to weigh the credentials and expertise of the speakers, but to decide on instinct who is more emotionally credible. Even if a television programme is convinced to not air graphic images of animals, an actress weeping about the fate of a puppy will carry more weight than a dry scientist with a logical defence. And, to top it all, scientists are often poor communicators.

In cases where scientists fear that their funding will be cut or their lab closed down, they should make their case to politicians, or to the public, through the less-emotional medium of print reporting. In cases where scientists face fanatical activists, that threat will always remain, whether

"Film sequences of animal experimentation trigger intense reactions in viewers. The screech of a monkey or whine of a dog drowns out every possible justification.'

\section{scientists can use it to their advantage}

Many things that are good for society as a whole would not survive a plebiscite on how public funds should be spent. Against the backdrop of worldwide budget cuts, an open discussion about the cost-benefit ratio of high-energy physics (or opera) might not be good for the field.

We should not encourage television to draw attention to debates that can't be won, or to topics that do better left entirely out of the spotlight. Anyone who makes the mistake of trying to present the complex story of animal experimentation through the colourful lens of television will end up in darkness.

Ranga Yogeshwar is a science journalist based near Cologne, Germany. He presents several television programmes in Germany and writes popular science books, including Ach, so! (2010). e-mail:info@yogeshwar.de

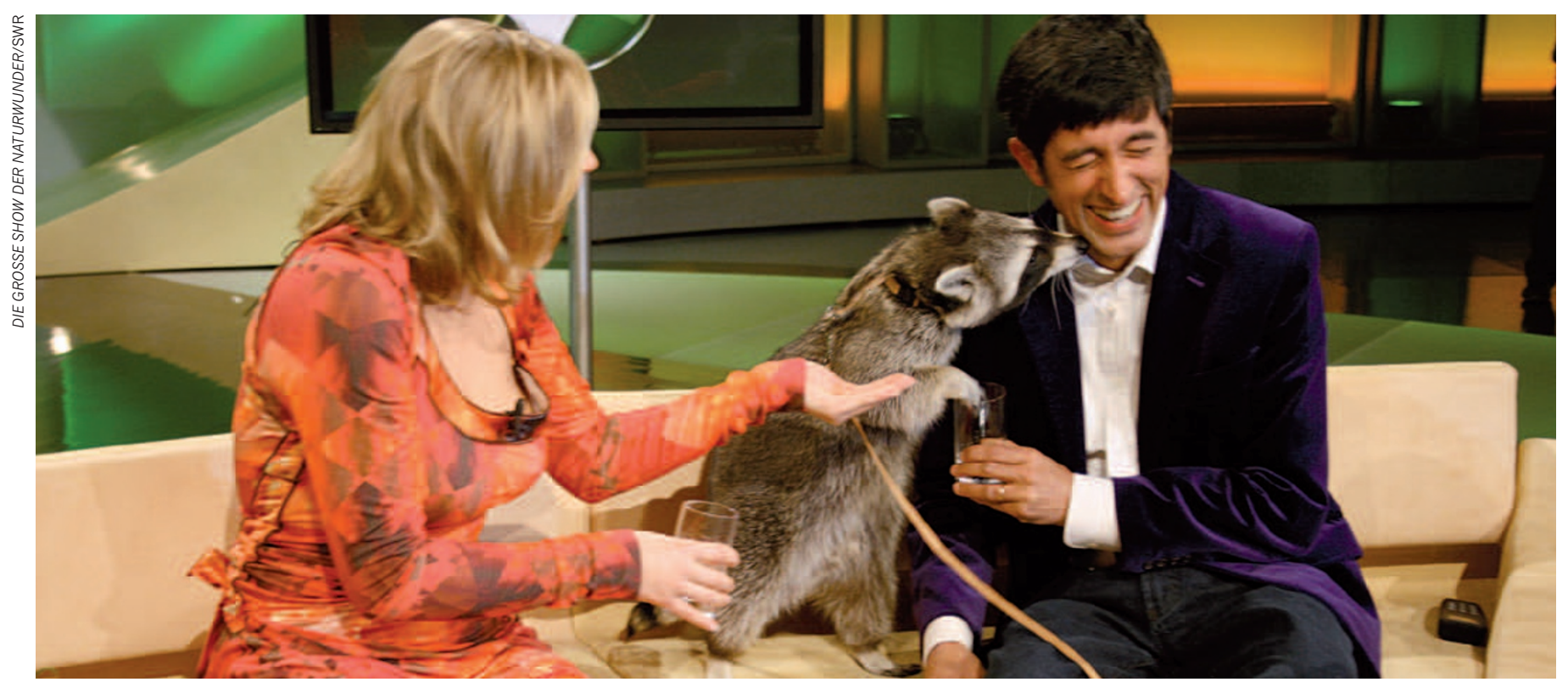

Only some animal research comes across well on television: Ranga Yogeshwar (right) with a raccoon on Die große Show der Naturwunder. 